\title{
Experimental Research on the Flexural Capacity of Reinforced Concrete Beams Reinforced with BFRP
}

\author{
Cheng Haigen ${ }^{1, *}$, Tian $^{\text {Qin }}{ }^{2}$, Shang Jingmiao ${ }^{1}$ and Lu Dinkun ${ }^{1}$ \\ ${ }^{1}$ School of Civil Engineering, East China Jiaotong University, Nanchang Jiangxi, 330013, P.R. China; ${ }^{2}$ School of Civil \\ Engineering, Nanchang University, Nanchang Jiangxi, 330013, P.R. China
}

\begin{abstract}
In order to study the ultimate flexural capacity of reinforced concrete beams with BFRP (Basalt fiber reinforced polymer), the test is designed and poured four T-section reinforced concrete beams. At first, monotonous static loading is carried on two of the beams until the chinks appeared. Afterward, all beams are strengthened by BFRP sheets. The contrast experiment studied and analyzed the different cracking load, ultimate load, deflection, reinforcement strain, concrete strain, fiber cloth strain, crack development of pre-reinforced beams and damaged beams strengthened by BFRP sheets. At the same time, the theoretical analysis and finite element simulation are performed to verify the result of experiment. The results show that the ultimate flexural capacity of reinforced concrete beams with BFRP has significantly increased. The circular bead treatment raises woke effect and reduces stress concentration of BFRP sheets.
\end{abstract}

Keywords: Basalt fiber reinforced polymer, pre-reinforcement, T-section reinforced concrete beam, ultimate flexural capacity.

\section{INTRODUCTION}

Basalt fiber reinforced polymer (BFRP) is made from natural basalt ore, while the price of BFRP is $1 / 3$ the price of domestic carbon fiber material and $1 / 10$ the price of imported products respectively [1]. The advantage of BFRP is that its melting process does not produce alkali oxides and toxic and harmful gases. In addition, because the residual waste of underground landfill treatment for BFRP does not have effect on the soil pollution and water pollution, BFRP has a very good prospect. Although the research on BFRP is started relatively late in China, people recently focus on the BFRP research which has been considered as a key national plan [2]. Many researchers studied on the shear behavior and flexure behavior, but the contrast experiment is lacking [37]. Based on the previous study, this paper focuses on the ultimate flexural capacity of reinforced concrete beam with BFRP. The research methods are experiments combined with the theoretical analysis and finite element simulation.

\section{EXPERIMENTAL DESIGN}

\subsection{Manufacture and Material Properties of Test Beam}

Unlike the actual $\mathrm{T}$-section reinforced concrete beam with the length of $16 \mathrm{~m}$, the test reinforced concrete beams are manufactured by size reduction. The section of prototype beam is composed of seven T-section reinforced concrete beams. Based on the stress similitude, the dimension of test beam is shown in Fig. (1) and Fig. (2). Similarity ratios of the test beams are 1:13.3 and 1:2.5 for longitudinal and transverse directions respectively.

*Address correspondence to this author at the School of Civil Engineering, East China Jiaotong University, Nanchang, Jiangxi, 330013, P.R. China; Tel: 13879104029; E-mail: bridge407@126.com
There are four test beams in this study, which are divided into two groups. The test beams in one group are prereinforced beam, while the test beams in the other group can be used to simulate actual reinforcement beam. The number of beam, reinforcement ratio and flange height are shown in Table 1.

In this paper, concrete design strength grade is $\mathrm{C} 40$, while hot rolled ribbed bars (HRB335Ф12 and HRB335Ф10) are used as main steel bars. Ten hot rolled plain round bars (HPB235Ф6) equipped as stirrups and hot rolled plain round bars (HPB235Ф10) are adopted as supports. The measured mechanical property parameters of steel bars are presented in Table 2.

Basalt fiber reinforced polymer applied in this test is BUF9-300 produced in GBF Company. The material property parameters are illustrated in Table $\mathbf{3}$.

\subsection{Cracking Test Before Reinforcement}

In order to compare with the mechanical property parameters of pre-reinforcement concrete beam, loading tests for two test beams are carried out after 28 days maintenance. Fiber reinforced polymer sheets do not reinforce these two test beams. The compression force of the hoisting jack is 300 $\mathrm{kg} / \mathrm{cm}^{3}$, while the maximum output load is $30 \mathrm{t}$. The oil pump used in this test is manual pump made in De Zhou hydraulic equipment Company and each manual operation can generate $8 \mathrm{KN}$ of output load. Test results: For the beam of DB-1, two cracks appear in the region supported on two bearing supports when loading value is $168 \mathrm{KN}$. The angle of the crack is 45 degree, while the crack extends slowly. Near the region of bearing supports, the maximum crack width is $1.994 \mathrm{~mm}$, which is larger than the limit of crack width. Since the phenomena of concrete-flake-off appear in the region of bearing supports, the region is repaired by the 


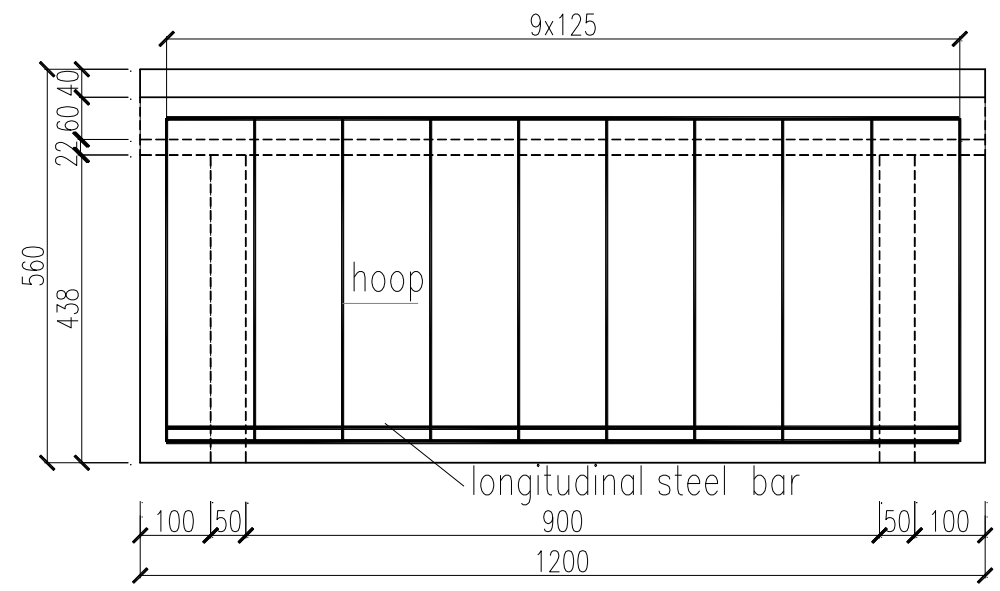

Fig. (1). Dimensions and reinforcements of test beams (unit:mm).
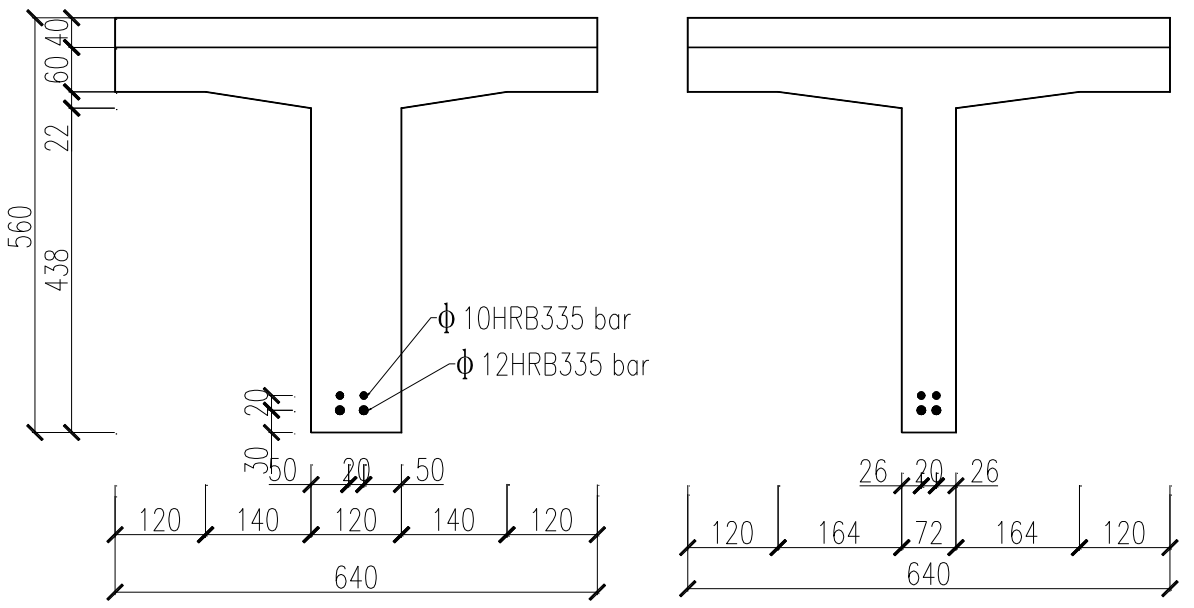

Fig. (2). Cross-section shape of test beams (unit:mm).

Table 1. Parameters of test beams.

\begin{tabular}{|c|c|c|c|}
\hline Numbering & Reinforced Case & $\begin{array}{l}\text { Depth of the Designed Flange } \\
\qquad(\mathrm{mm})\end{array}$ & $\begin{array}{l}\text { Depth of the Actual Flange } \\
(\mathbf{m m})\end{array}$ \\
\hline DB-1 & \multirow{3}{*}{$\begin{array}{l}\text { Tensile reinforcement is divided into two layers. First layer } \\
\text { includes two } \Phi 12 \text { bars of HRB335. Second layer includes two } \\
\Phi 10 \text { bars of HRB335. Stirrup spacing is } 125 \mathrm{~mm} \text {. Stirrup is } \Phi 6 \\
\text { bar of HPB } 235 .\end{array}$} & 100 & 98 \\
\hline DB-2 & & 100 & 108 \\
\hline YJG-1 & & 100 & 106 \\
\hline
\end{tabular}

Table 2. Steel mechanical property.

\begin{tabular}{|c|c|c|c|c|}
\hline Model & $\begin{array}{c}\text { Diameter } \\
\text { /mm }\end{array}$ & $\begin{array}{c}\text { Yield Strength } \\
\text { /MPa }\end{array}$ & $\begin{array}{c}\text { Tensile Strength } \\
/ \text { Mpa }\end{array}$ & $\begin{array}{c}\text { Elongation } \\
/ \%\end{array}$ \\
\hline \hline HPB235 & 6 & 326.4 & 468.4 & 24 \\
\hline HRB335 & 12 & 383.7 & 551.5 & 19 \\
\hline
\end{tabular}


Table 3. Parameters of basalt fiber cloth material.

\begin{tabular}{|c|c|c|c|c|c|}
\hline Product Model & $\begin{array}{c}\text { Unit } \\
\text { Weight } \\
\left(\mathbf{g} / \mathbf{m}^{\mathbf{2}}\right)\end{array}$ & $\begin{array}{c}\text { Design Thickness } \\
/ \mathbf{m m}\end{array}$ & $\begin{array}{c}\text { Tensile } \\
\text { Strength } \\
/ \text { Mpa }\end{array}$ & $\begin{array}{c}\text { Young's Modulus } \\
/ \text { Gpa }\end{array}$ & $\begin{array}{c}\text { Extension Rate } \\
/ \%\end{array}$ \\
\hline \hline BUF9-300 & 300 & 0.109 & $\geq 2100$ & $\geq 93$ & $\geq 3.1$ \\
\hline
\end{tabular}

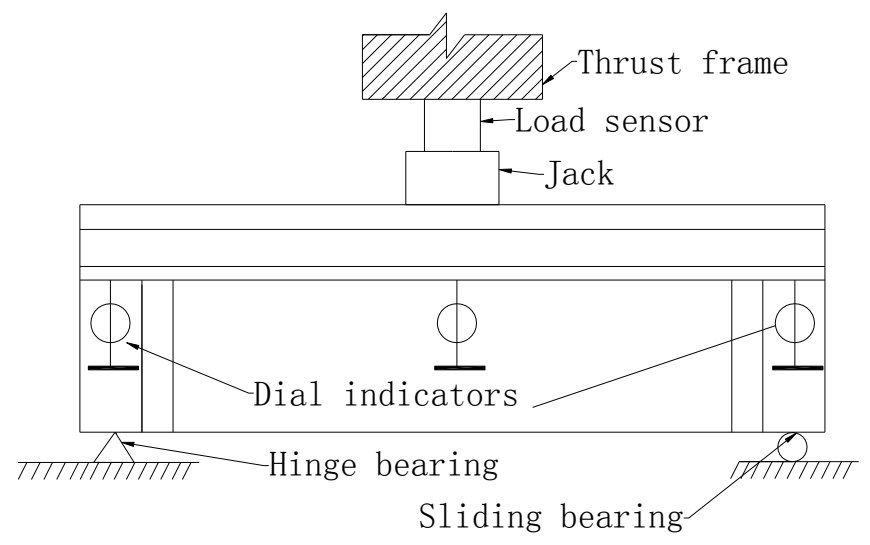

Fig. (3). Loading mode.

Table 4. Non-reinforcement beam characteristics.

\begin{tabular}{|c|c|c|}
\hline Number & Whether Existing Cracks & Whether Corners are Rounded Surfaces \\
\hline \hline DB-1 & yes & no \\
\hline DB-2 & yes & nes no \\
\hline YJG-1 & no & yos \\
\hline YJG-2 & no & nes \\
\hline
\end{tabular}

concrete mixed reinforcement adhesives. For the beam of DB-2, three cracks appear between bearing support and beam centroid, when loading value is $220 \mathrm{KN}$. The maximum crack width is $0.604 \mathrm{~mm}$, which is also larger than the limit of crack width. Loading mode is shown in Fig. (3).

\subsection{Reinforcement Scheme}

When carbon fiber sheet pastes on the concrete member, the curvature radius should be larger than $20 \mathrm{~mm}$ at the surface of the concrete member corner. However, because it is very difficult to deal with the complicated corner, the angle is 90 degree at the corner in actual engineering. The effect of circular bead treatment on the experiment results is considered in this test. In the four T-section beams, DB-1 and DB-2 are loaded until cracks before the test, while YJG-1 and YJG-2 keep intact. For DB-1 and YJG-1, the angle at the web bottom corner is 90 degree. For DB-2 and YJG-2, the radius is $20 \mathrm{~mm}$ at the web bottom corner. The properties of the four T- section beams are shown in Table 4.

When basalt fiber reinforced polymer is used to reinforce the positive bending moment area of $\mathrm{T}$ - section beam, the basalt fiber reinforced polymer length should extend to the bearing supports edge. The truncation place of the carbon fiber sheet is determined by the full use of section $[8,9]$. The extent length of carbon fiber sheet is $580 \mathrm{~mm}(430+150)$, while the width of carbon fiber sheet is $72 \mathrm{~mm}$. The measured deviation is $\pm 2 \mathrm{~mm}$. Two layers of carbon fiber sheets are applied at the beam bottom, while the actual thickness is $0.218 \mathrm{~mm}(2 \times 0.109)$.

Two sides of the web for T-section beam are anchored by carbon fiber sheet U-shaped hoop, while the paste height is $348 \mathrm{~mm}$. Two sides of the web are equipped with three Ushaped hoops, the width and clear spacing are $200 \mathrm{~mm}$ and $75 \mathrm{~mm}$ respectively.

Diagonal section of test beam is reinforced by U-shaped hoop which is fixed to the attached fiber cloth above it. The fiber cloth is one layer of $900 \mathrm{~mm} \times 90 \mathrm{~mm}$ fabric, which is close to the flange at the bottom [10].

The paste order of carbon fiber sheet is shown as follows: carbon fiber sheet at the beam bottom $\rightarrow U$-shaped hoop carbon fiber sheet at two sides of web $\rightarrow$ cover U-shaped hoop with carbon fiber sheet. Paste position and size are shown in Fig. (4). 


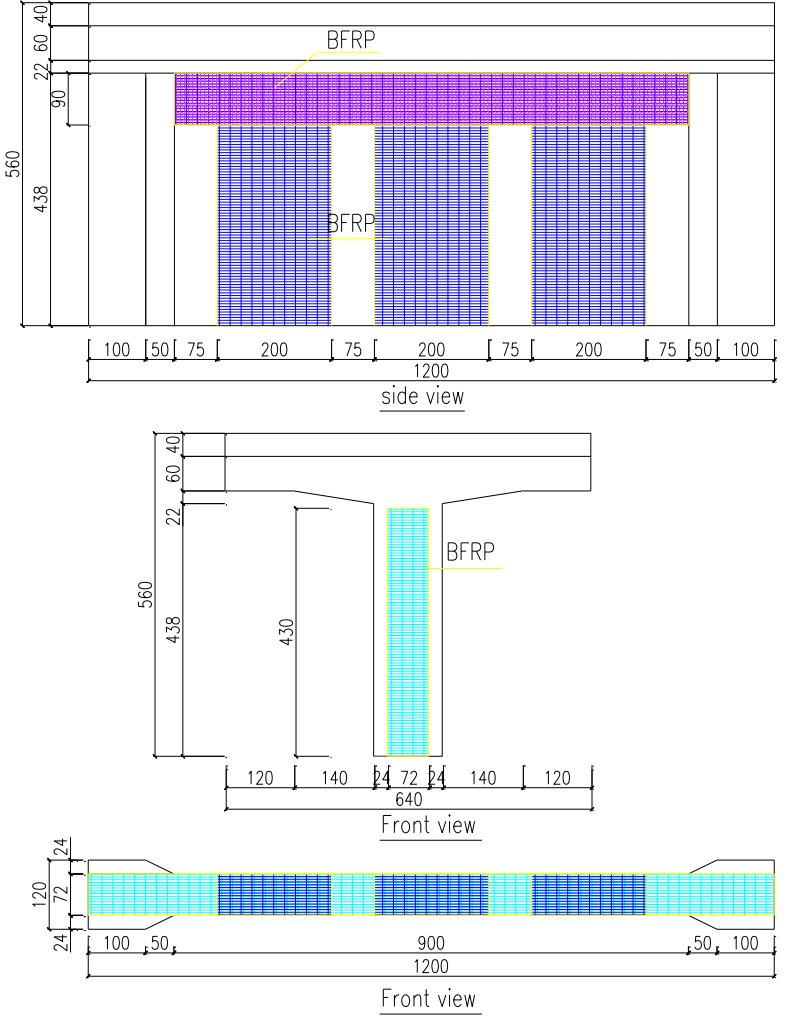

Fig. (4). Positioning map of BFRP sheets (unit:mm).

\subsection{Strain Gauge Arrangement}

The strain gauges are pasted on the main steel bars of Tsection beam at mid-span before pouring the concrete. After the carbon fiber sheet is pasted on the beam bottom, the strain gauges are pasted on the web U-shaped hoop and oblique section at mid span. Strain gauge specification is shown in Table 5.

In order to make sure the objectivity of the test results, more strain gauges are pasted on the beam. Four strain gauges are symmetrically pasted on the main steel bar. Two pieces of strain gauges are symmetrically pasted on flange of mid-span along the longitudinal direction. The distance from one of the strain gauges to cross-sectional symmetry axis is $160 \mathrm{~mm}$. Two pieces of strain gauges are symmetrically pasted on the tensile fabric cloth of bottom surface of the mid- span tension zone. Four pieces of strain gauges are pasted on U-shaped hoop of web, its margin increases from bottom to top. Four pieces of strain gauges are symmetrically pasted on oblique section. Strain gauge glued location and spacing are shown in Fig. (5).

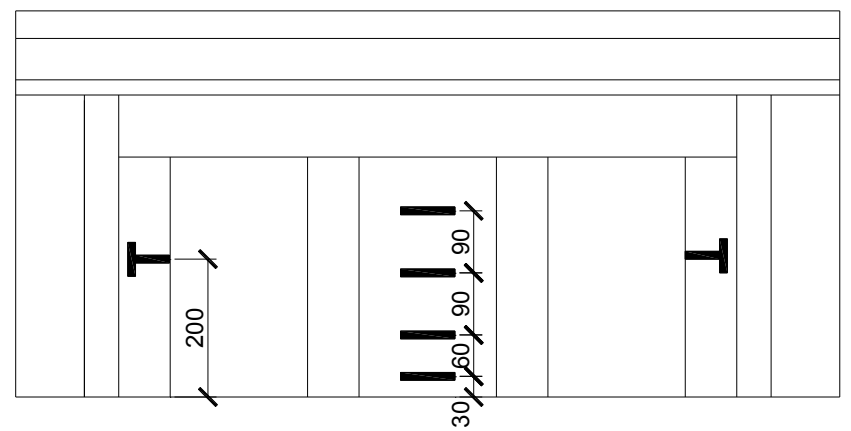

Fig. (5). Strain gauge glued location (unit: $\mathrm{mm}$ ).

\subsection{Test Process}

In order to check the working performance of the test equipment, preloading of the reinforced beam is carried out before the test. The maximum preloading value is $70 \%$ of the maximum cracking load. During the test, cracks do not appear in the reinforced beam. Loading test method is step loading, and each step loading is $20 \mathrm{KN}$. The limit loading time is $60 \mathrm{~s}$, while the time under sustained loading is $120 \mathrm{~s}$. Because the deformation is stable, the strain, crack width and reading data of the dial indicator can be easily recorded.

\section{THEORETICAL ANALYSIS AND FINITE ELE- MENT SIMULATION}

\subsection{Theoretical Analysis}

\subsubsection{Bearing Capacity of Normal Section}

Based on the previous study, the strengthened section equation of reinforced concrete beam is illustrated in related literature [11].

According to the formula

$$
\begin{aligned}
& \alpha_{1} f_{c}\left[b x+\left(b_{f}{ }^{\prime}-b\right) h_{f}{ }^{\prime}\right]=f_{y} A_{s}+f_{p y} A_{p} \\
& x=66.046 \mathrm{~mm}>h_{f}{ }^{\prime}=60.00 \mathrm{~mm}
\end{aligned}
$$

Table 5. Specifications of strain gauges on different sticking positions.

\begin{tabular}{|c|c|c|c|c|}
\hline Sticking Position & Model & $\begin{array}{c}\text { Resistance } \\
/ \mathbf{\Omega}\end{array}$ & $\begin{array}{c}\text { Gate Length } \times \text { Gate Width } \\
/ \mathbf{m m}\end{array}$ & Sensitivity Coefficient \\
\hline \hline Steel bar & $\begin{array}{c}\text { BX120 } \\
-2 \mathrm{AA}\end{array}$ & 120.5 & $2 \times 1$ & \pm 2.00 \\
\hline Concrete & $\begin{array}{c}\text { BX120 } \\
-80 \mathrm{AA}\end{array}$ & 120.9 & $80 \times 3$ & \pm 2.00 \\
\hline Fiber cloth & $\begin{array}{c}\text { BX120 } \\
\text {-50AA }\end{array}$ & 120.6 & $50 \times 3$ & \pm 2.00 \\
\hline
\end{tabular}


The test beam is second class T-section beam, according to the following formula :

$$
M \leq \alpha_{1} f_{c 0} b x\left(h_{0}-\frac{x}{2}\right)+\alpha_{1} f_{c 0}\left(b_{f}^{\prime}-b\right) h_{f}^{\prime}\left(h_{0}-\frac{b_{f}^{\prime}}{2}\right)
$$

The maximum design bending moment $\mathrm{M}=52.57 \mathrm{kN} \cdot \mathrm{m}$. Loading location is at mid span in the test, while the maximum load capacity is $\mathrm{N}=175.24 \mathrm{kN}$.

The carbon fiber sheet size can be substituted into the formula [12]:

$$
k_{m}=1.16-\frac{n_{f} E_{f} t_{f}}{30800}
$$

Solution: $k_{m}=1.011>0.90$

So $k_{m}$ is 0.90 , the effective cross section area of the carbon fiber sheet is calculated as per the following formula.

$$
\begin{aligned}
A_{f e} & =A_{f} k_{m}=72 \times 0.109 \times 2 \times 0.90 \\
=14.126 \mathrm{~mm}^{2} & \\
\psi_{f} & =\frac{\left(0.8 \varepsilon_{c u} h / x\right)-\varepsilon_{c u}-\varepsilon_{f 0}}{\varepsilon_{f}} \\
& =\frac{0.8 \times 0.0033 \times 520 / 104.753-0.0033-0}{0.01} \\
& =0.98<1.0
\end{aligned}
$$

According to the formula

$\alpha_{1} f_{c 0} b x=f_{s 0} A_{s 0}+\psi_{f} f_{f} A_{f e}$

Solution results : $x=104.753 \mathrm{~mm}$,

$$
\begin{aligned}
M & \leq \alpha_{1} f_{c 0} b x\left(h-\frac{x}{2}\right)+\alpha_{1} f_{c 0}\left(b_{f}{ }^{\prime}-b\right) h_{f}{ }^{\prime}\left(h_{0}-\frac{h_{f}{ }^{\prime}}{2}\right) \\
& -f_{y 0} A_{s}\left(h-h_{0}\right)
\end{aligned}
$$

Solution results: the maximum design bending moment after reinforcement, $\mathrm{M}=66.91 \mathrm{KN} \cdot \mathrm{m}$, the increase value is $27.28 \%$. The ultimate bearing capacity is $223.04 \mathrm{KN}$ in the case of the design loading at mid span.

\subsubsection{Load Capacity of Oblique Section}

$\lambda=\frac{a}{h_{0}}=1.02$

取 $\lambda=1.5$ 。

$\sigma_{x}=\frac{1.75}{\lambda+1}=0.7$

$$
\begin{aligned}
V_{c s} & =\alpha_{c v} f_{t} b h_{0}+f_{y v} \frac{A_{s v}}{s} h_{0} \\
& =0.7 \times 1.71 \times 72 \times 490+235 \times \frac{5 \times 28 \times 27}{120} \times 490 \\
& =177.867 \mathrm{KN}
\end{aligned}
$$

The design value of the shear capacity $\mathrm{Vcs}=177.87 \mathrm{KN}$ 。 $h_{w} / b=6.388>6$

Based on the formula $V \leq 0.2 \beta_{c} f_{c} b h_{0}$, the design maximum value of the shear capacity of oblique section is $134.77 \mathrm{KN}<V_{\text {cso }}$

The design width and clear spacing of U-shaped hoop can be substituted into the formula:

$$
\begin{aligned}
V_{b f} & =\psi_{v b} f_{f} A_{f} h_{f} / s_{f} \\
& =\frac{0.58 \times(0.56 \times 2100) 95.484 \times 438}{275} \\
& =103.73 \mathrm{KN} \\
V & \leq V_{b 0}+V_{b f}=238.5 \mathrm{kN}
\end{aligned}
$$

Solution results: The design value of the shear capacity after reinforcement, $\mathrm{V}=238.5 \mathrm{KN}$ 。

\subsection{Finite Element Model}

Finite element analysis is carried out by the software of ANSYS. The elements of Solid 65 and Link 8 can be used to simulate concrete and steel bar respectively. The mesh generation and the loading are shown in Fig. (6).

The ultimate bearing capacity of reinforcement beam model is $296.42 \mathrm{KN}$, while the displacement at mid-span is $14.70 \mathrm{~mm}$. The steel strain and stress are $1671 \mu \varepsilon$ and 334.2 MPa respectively. The carbon fiber sheet strain in the tension area is $1694 \mu \varepsilon$.

\section{THE TEST RESULTS AND ANALYSIS}

\subsection{Loading Test and Damage Condition \\ 4.1.1. Loading Test Damage for DB-1 Beam}

When loading value is $60 \mathrm{KN}$, origin crack decreases from $1.444 \mathrm{~mm}$ to $1.320 \mathrm{~mm}$ because of bearing restraining. When loading value is $140 \mathrm{KN}$, the crack width gradually increases and the deflection at mid-span is $0.49 \mathrm{~mm}$. When loading value is $220 \mathrm{KN}$, the crack width is $2.592 \mathrm{~mm}$ and the deflection at mid-span is $0.78 \mathrm{~mm}$. The steel stress and strain are $89.676 \mathrm{MPa}$ and $448.38 \mu \varepsilon$ respectively. The sound of U-shaped hoop and cover strip generates, while the crack width near the U-shaped hoop is $0.84 \mathrm{~mm}$. When loading is continuous, the concrete near the bearing is damaged, while steel strain and the deflection at mid-span increase. When loading is $265 \mathrm{KN}$, the size of two cracks sharply increases. The concrete near the bearing begins to fall off, while the shear break of carbon fiber sheet occurs near the bearing. The displacement at mid-span transiently decreases. Both sides of the cover strip and U-shaped hoop appear peeling phenomenon at crack area. Because the beam of DB-1 is damaged, the reading of loading sensor decreases. The deflection at mid-span is $10.06 \mathrm{~mm}$, while steel bar strain and stress are $507.8 \mu \varepsilon$ and101.56 MPa respectively. When the loading is applied on the beam of DB-1, both the width of the crack and the damage degree of the beam are large. The ultimate load can be greatly promoted after reinforcement, but the damaged concrete has effect on the ultimate load to a certain degree. The beam of DB-1 quickly presents brittle failure pattern when carbon fiber sheet and concrete are separated, as shown in Fig. (7). 


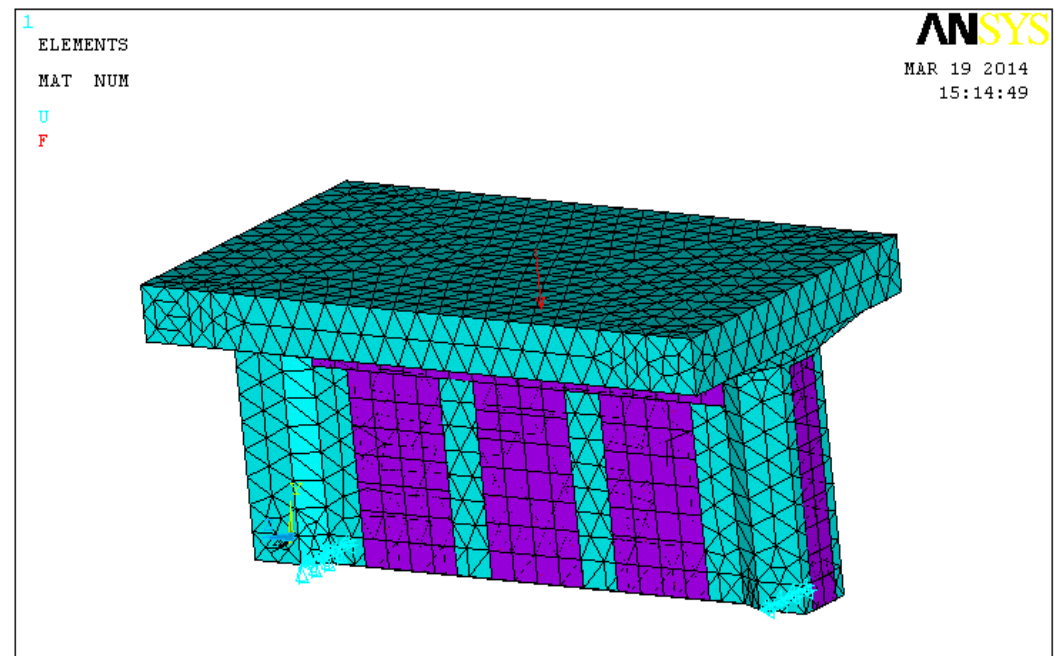

Fig. (6). Element division and loading of test beams.

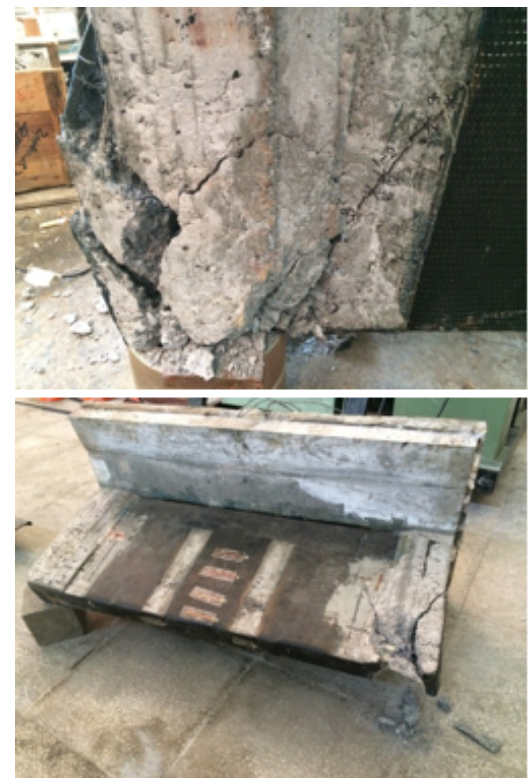

Fig. (7). The failure mode of Team DB-1.

\subsubsection{Loading Test Damage for DB-2 Beam}

When loading value is $120 \mathrm{KN}$, the width of crack is $0.098 \mathrm{~mm}$. After that the width of crack obviously increases. As the loading value is $320 \mathrm{KN}$, the extension of crack is obvious and the cracks extend to the flange bottom of the mid-span. Many new fine cracks appear in the area near the origin cracks, while the width of new cracks is less than 0.05 $\mathrm{mm}$. The deflection at mid-span is $2.56 \mathrm{~mm}$, and steel tension strain is $1279.7 \mu \varepsilon$. The steel compression strain at midspan is $565.09 \mu \varepsilon$. When loading reaches $380 \mathrm{KN}$, the sound of U-shaped hoop comes out. The width of new cracks becomes large. When loading value is $420 \mathrm{KN}$, some part of Ushaped hoop appears fracture. Cover strip separates from concrete face, while the deflection at mid-span increases. The steel strain and steel stress are $1631.18 \mu \varepsilon$ and 326.236 $\mathrm{MPa}$ respectively. The steel strain in compression area is $757.33 \mu \varepsilon$. The recorded maximum loading is $446 \mathrm{KN}$. The peeling phenomenon between U-shaped hoop and cover strip obviously appears. The deflection at mid-span sharply in-

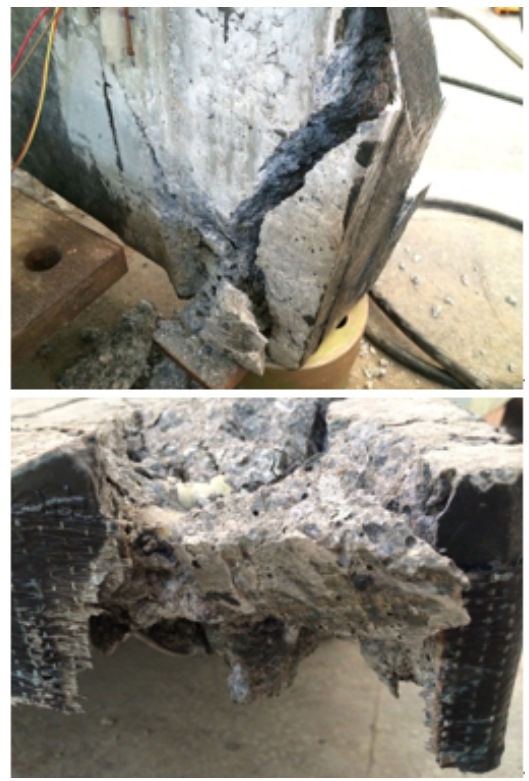

creases, and the carbon fiber sheet is cut at bearing support. The width of crack extends to $18.76 \mathrm{~mm}$. The width of the crack at flange bottom is $3.42 \mathrm{~mm}$. At the same time, the concrete fall off at bearing support. Based on the above statements, the beam of DB-2 is completely destroyed, as shown in Fig. (8).

\subsubsection{Loading Test Damage for YJG-1 Beam}

When loading value reaches $160 \mathrm{KN}$, the extension sound of carbon fiber sheet is obvious. The deflection at mid-span is $0.95 \mathrm{~mm}$, while steel strain and carbon fiber sheet strain are $696.16 \mu \varepsilon$ and $31.07 \mu \varepsilon$ respectively. The concrete strain at compression area is $144.67 \mu \varepsilon$. When loading is $240 \mathrm{KN}$, the sound of U-shaped hoop is obvious. The extension force of carbon fiber sheet increases. When loading is $280 \mathrm{KN}$, many cracks of oblique section symmetrically appear. The width of crack extends to $0.42 \mathrm{~mm}$. The angle between the crack and the horizontal line is $36.2^{\circ} \sim 43.7^{\circ}$. At the same time, the deflection at mid-span is $4.27 \mathrm{~mm}$, while the strain of carbon fiber sheet in extension area is 1444.76 

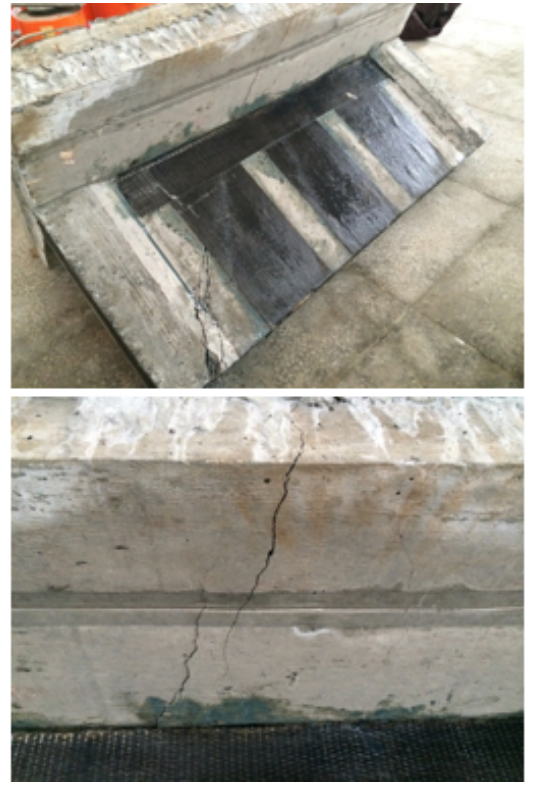

Fig. (8). The failure mode of Team DB-2.
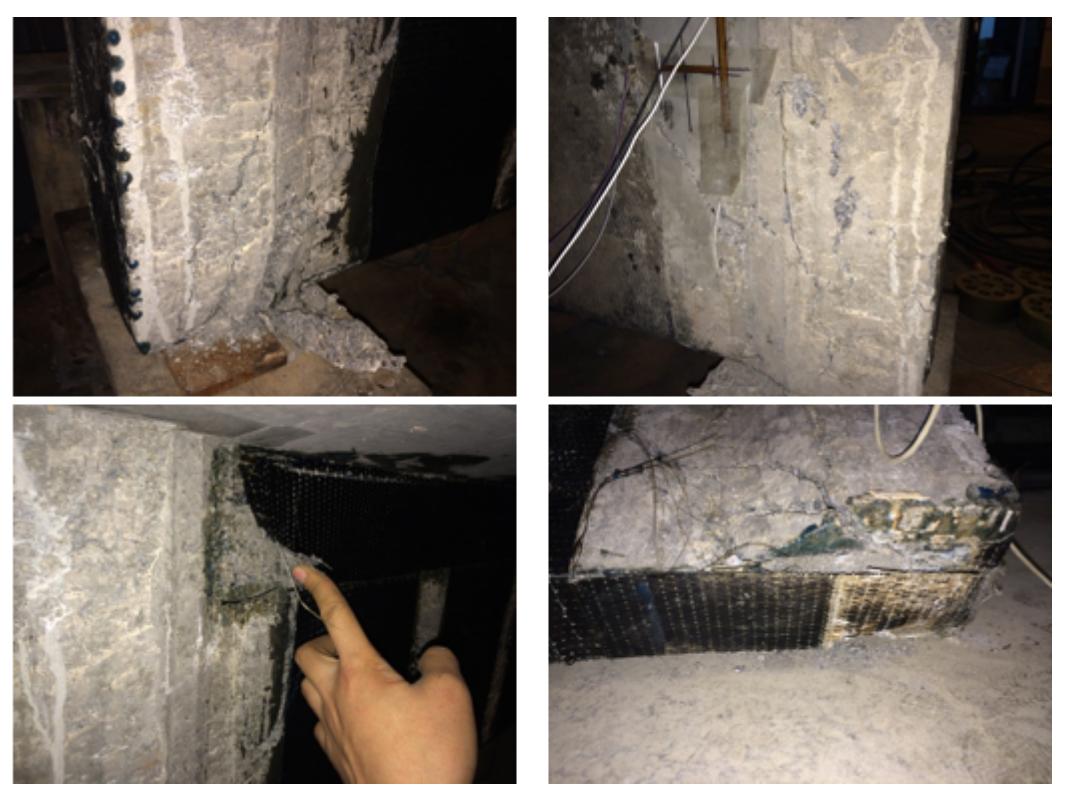

Fig. (9). The failure mode of Team YJG-1.

$\mu \varepsilon$. Steel strain and steel stress are $1304.94 \mu \varepsilon$ and 260.988 $\mathrm{MPa}$ respectively. The concrete strain in compression area is $325.27 \mu \varepsilon$. When loading is $328 \mathrm{KN}$, the width of crack extends to $16.82 \mathrm{~mm}$ at the bending shear region. The concrete at bearing support fall off and the peeling between U-shaped hoop and cover strip appears. The deflection at mid-span reaches the maximum value, while the beam of YJG-1 is damaged, as shown in Fig. (9).

\subsubsection{Loading Test Damage for YJG-2 Beam}

When loading value reaches $240 \mathrm{KN}$, the extension sound of carbon fiber sheet is obvious. The deflection at mid-span is $2.34 \mathrm{~mm}$, while steel strain and carbon fiber sheet strain are $1340.87 \mu \varepsilon$ and $1169.98 \mu \varepsilon$ respectively. The concrete strain at compression area is $293.22 \mu \varepsilon$. When loading value is $340 \mathrm{KN}$, the width of crack on the bearing sup-

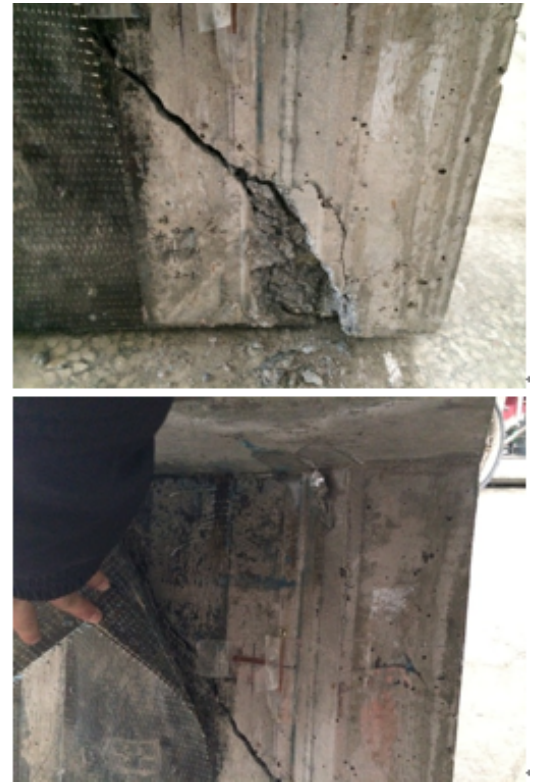

port is less than $0.2 \mathrm{~mm}$. The deflection at mid-span is 2.93 $\mathrm{mm}$, while steel strain and carbon fiber sheet strain are $1634.09 \mu \varepsilon$ and $1470 \mu \varepsilon$ respectively. The concrete strain at compression area is $354.37 \mu \varepsilon$. The width of crack gradually increases with the increase of loading. New vertical cracks appear, while the cover concrete begins to fall off. When loading value is $400 \mathrm{KN}$, the width of crack is $1.56 \mathrm{~mm}$. Carbon fiber sheet generates sound during loading process. Cover strip and concrete separates, while U-shaped hoop and concrete also separates. The separating area gradually increases and cracks of some carbon fiber sheets extend to the bottom of U-shaped hoop. The variation rate of deflection at mid-span obviously increases, while increasing rate of carbon fiber sheet strain deceases and the steel strain continues increasing. When loading value is $426 \mathrm{KN}$, flexural and tensile carbon fiber sheets at bearing support are neatly 

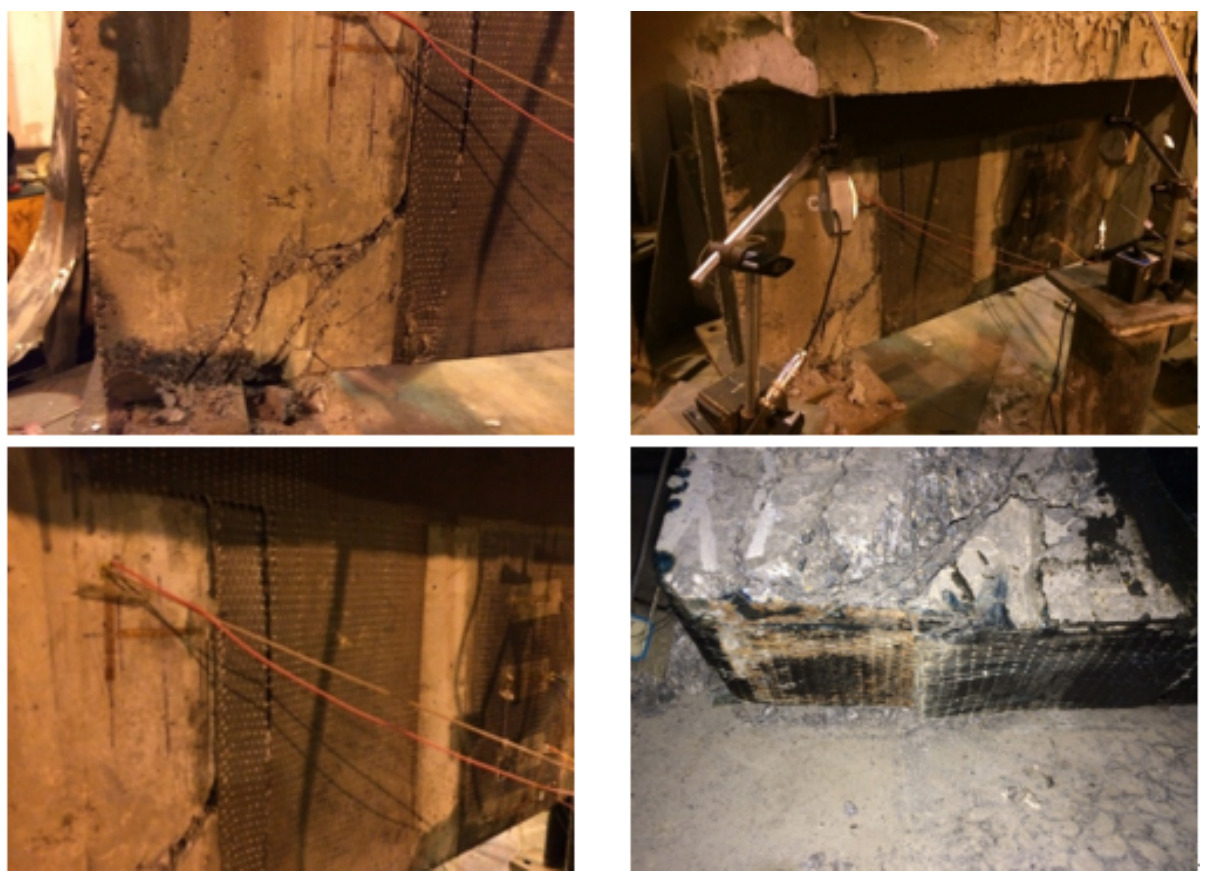

Fig. (10). The failure mode of Team YJG-2.

Table 6. Ultimate bearing capacity of fiber reinforced concrete beam.

\begin{tabular}{|c|c|c|c|}
\hline Number & $\begin{array}{c}\text { Ultimate Bearing } \\
\text { Capacity of Test Values } \\
\text { KN }\end{array}$ & $\begin{array}{c}\text { Improved } \\
\text { Ratio } \\
\%\end{array}$ & Failure Modes \\
\hline DB-2 & 446 & 87.4 & $\begin{array}{l}\text { Tensile fabric parts are torn to disconnect, u-shaped clamps and cover are stripped off, partial } \\
\text { concrete are broken off, cracks of flange bottom are noticeable. }\end{array}$ \\
\hline YJG-1 & 328 & 37.8 & $\begin{array}{l}\text { Tensile fabric of supports are cut off, u-shaped clamps and cover are stripped off, partial con- } \\
\text { crete of supports are broken off. }\end{array}$ \\
\hline YJG-2 & 426 & 79.0 & $\begin{array}{l}\text { Tensile fabric of supports are cut off, u-shaped clamps and cover are stripped off, cracks about } \\
\text { flexure-shear zone of concrete are noticeable. }\end{array}$ \\
\hline
\end{tabular}

cut. Both the U-shaped hoop and the cover strip are separated from concrete. The maximum deflection at mid-span is $18.81 \mathrm{~mm}$, while steel strain and steel stress are $1791.39 \mu \varepsilon$ and $358.278 \mathrm{MPa}$ respectively. The maximum strain of carbon fiber sheet is $1632.15 \mu \varepsilon$. The concrete strain in compression area is $419.45 \mu \varepsilon$. The reading of loading suddenly changes, while the beam of YJG-2 is completely damaged, as shown in Fig. (10).

\subsection{Analysis of Test Results}

The ultimate bearing capacity of the pre-reinforcement concrete beam and reinforcement concrete damaged beam is shown in Table 6.

The main tensile steel bars in reinforced concrete beam are $\Phi 12 \mathrm{HRB} 335$ and $\Phi 10 \mathrm{HRB} 335$. Concrete cover thickness is $30 \mathrm{~mm}$. Load-strains curves are shown in Fig. (11) and Fig. (12).
According to Fig. (11) and Fig. (12) because there is no slip between steel and concrete before the loading value is $300 \mathrm{KN}$, the stress of the steel bar in pre-reinforcement beam obviously changes. The deformation of beam can be effectively reduced. However, when loading value is over 300 $\mathrm{KN}$, the cracks appear in the concrete and the capacity of the steel bar decreases to a certain degree. It is that carbon fiber sheet affords bending moment.

Strain gauges on carbon fiber sheet are glued on both sides of U-shaped hoop at mid-span. Strain curves are shown in Fig. (13).

According to Fig. (13), carbon fiber sheet of prereinforcement beam can work together with steel bar earlier. Carbon fiber sheet strain of pre-reinforcement beam is larger than that of comparison beam. Because concrete cover is damaged, carbon fiber sheet affords most of the tensile stress. When the loading is $400 \mathrm{KN}$, the strain of carbon fiber sheet sharply increases. 


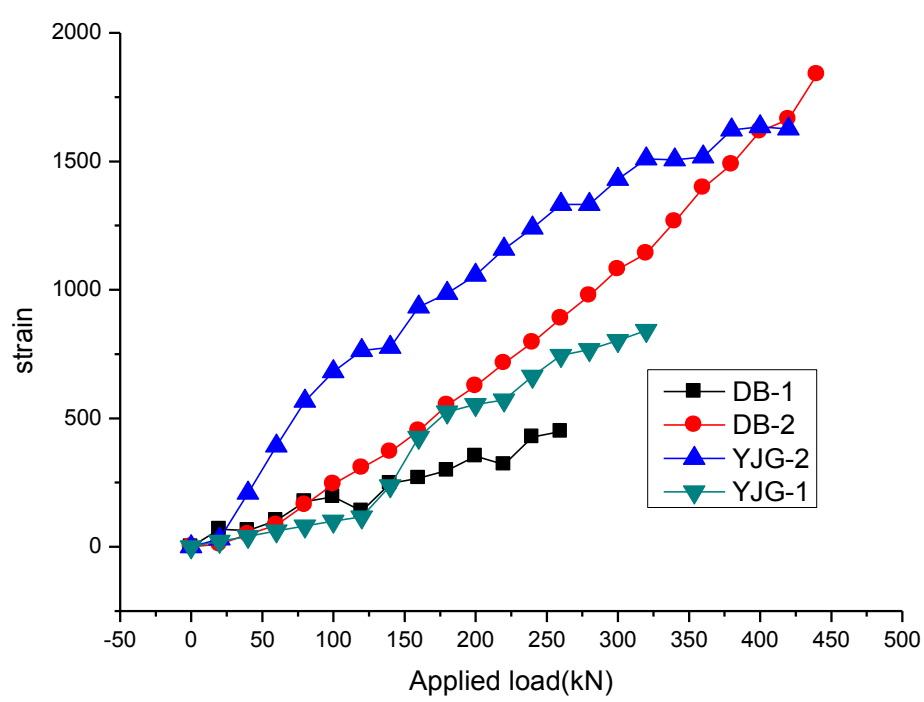

Fig. (11). Load-strains curves of $\Phi 12$ steel.

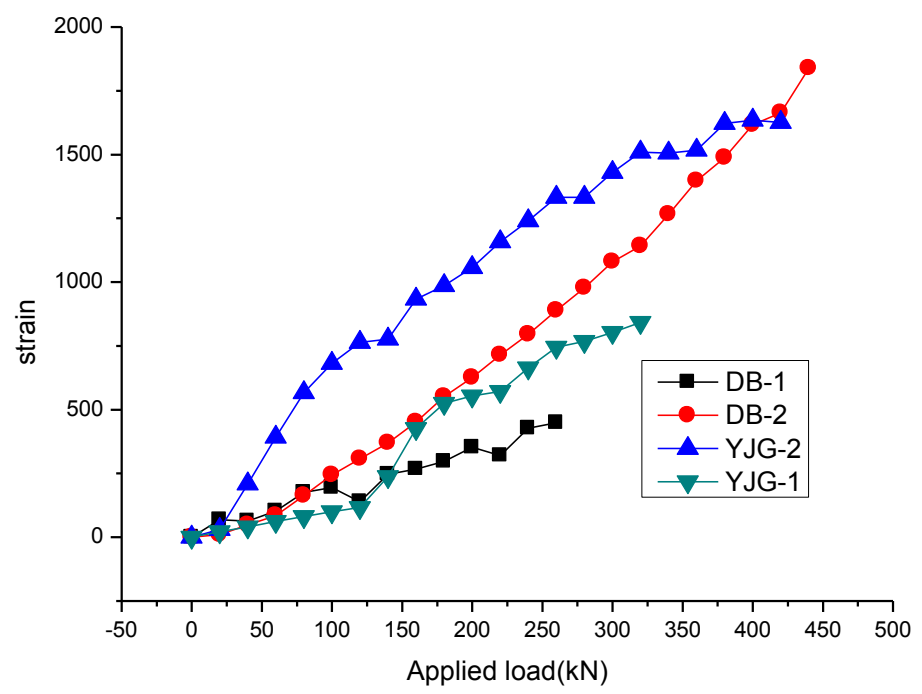

Fig. (12). Load-strains curves of $\Phi 10$ steel.

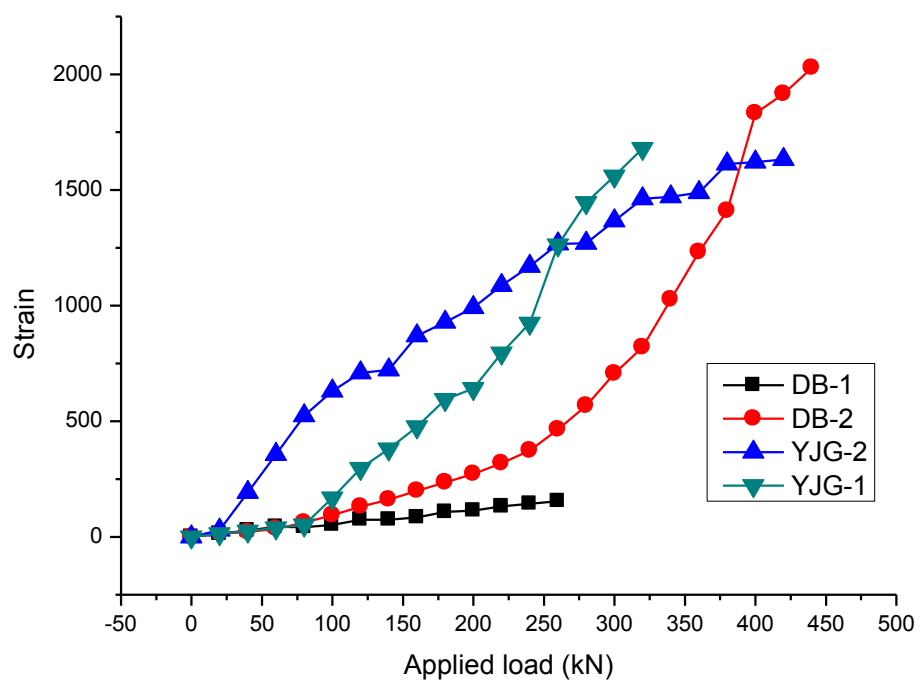

Fig. (13). Load-strains curves of tension fiber cloth. 


\section{CONCLUSION}

According to the results of test on four reinforcement beams, the following conclusions can be made.

(1) Both cracking load and yield load of the reinforcement beams can be obviously improved. Cracking rate of concrete is reduced because of carbon fiber sheets extension force effects. When the loading reaches the ultimate load, carbon fiber sheet affords tensile stress of the beam. The strain of carbon fiber sheet approaches or exceeds the strain of steel bar.

(2) Comparing with reinforcement damaged beam, carbon fiber sheet of pre-reinforcement beam can afford external force together with steel bar. The strain of carbon fiber sheet has similar value with the strain of steel bar. In addition, the stiffness of pre-reinforcement beam is larger than the one of reinforcement damaged beam. The deflection of pre-reinforcement beam at mid-span is less than the one of reinforcement damaged beam at late phase of loading. The stiffness can be significantly improved for the prereinforcement beam.

(3) The protective effect is better for flexure and shear zone of the concrete in the case of pre-reinforcement beam. The failure pattern of pre-reinforcement beam includes peeling or shear break of carbon fiber sheet. In addition, there are many cracks in the concrete of pre-reinforcement beam. However, the phenomena of concrete-flake-off occur before the peeling of carbon fiber sheet for reinforcement damaged beam.

(4) Flexural behavior is better than shear behavior for the test beam due to the effects of carbon fiber sheet layers and U-shaped hoop anchoring type. Therefore, the failure patterns are concrete crush damage and carbon fiber sheet bond failure, but the tension failure of carbon fiber sheet does not occur. In order to overcome the above damage types, wooden formwork can be used to compact the carbon fiber sheet. Therefore, the high strength of carbon fiber sheet can be made full use of.

(5) The circular bead treatment of the test beam could improve the function of carbon fiber sheet and U-shaped hoop. The stress concentration at the corner of beam can be obviously reduced, while the ultimate load can also be significantly improved.

(6) According to Code for design of concrete structures and Code for design of strengthening concrete structure, the- oretical derivation of the design ultimate bearing capacity of normal section and the design ultimate bearing capacity of oblique section can be obtained respectively. Comparing with the test results, the numerical solution of ANSYS is more safety.

\section{CONFLICT OF INTEREST}

The authors confirm that this article content has no conflict of interest.

\section{ACKNOWLEDGEMENTS}

The authors wish to acknowledge the support and motivation provided by the National Natural Science Foundation of China (Grant No. 51368018).

\section{REFERENCES}

[1] C. Zhou, "Production status of domestic carbon fiber material," $L u$ Tian Hua Ke Ji, vol. 3, pp. 221-225, 2011.

[2] J. Ni, "Research of Reinforced Concrete T-Beams Strengthened with BFRP“, M.S. thesis, Chongqing University, Chongqing, P.R. China, 2013.

[3] O. Yu, Y. Zhang, and X. Li, "The research on she-ar capacity of RC beams strengthened with BFRP sheets," Industrial Construction, vol. 39-1, pp. 134-137, 2009.

[4] Y. Sun, Y. Liu, and H. Hu, "Experimental study on reinforced concrete beams strengthened with BFRP," Journal of Qingdao Technological University, vol. 31-1, pp. 29-32, 2010.

[5] L. Wan, and Z. Chen, "Experiment research on reinforced concrete slabs strengthened by three kinds of FRPS," Structural Engineers, vol. 23-1, pp. 77-81, 2007.

[6] Y. Yang, X. Chen, J. Xing, J. Wang, and L. Hu, "Study on fatigue performance of reinforced concrete beams strengthened with BFRP sheet," Journal of Huaqiao University, vol. 31, no. 3, pp. 443-447, 2010 .

[7] L. Ouyang, B. Ding, and Z. Lu, "BFRP and its application review in structural strengthening," $F R P / C M$, vol. 3, pp. 84-88, 2010.

[8] "China association for engineering construction standardization," CECS 25:90 Technical Specification for Strengthening Concrete Structures, P.R. China, Beijing, 1990, pp. 5-35.

[9] "China association for engineering construction standardization," CECS 146: 2003 Technical Specification for Strengthening Concrete Structures with Carbon Fiber Reinforced Polymer Laminate, P.R. China: Beijing, 2003, pp. 8-14.

[10] L. Tan, GB 50367-2006 Design Code for Strengthening Concrete Structure, Beijing, P.R. China 2006, pp. 47-59.

[11] S. Zhao, "Design Principles of Reinforced Concrete Structure," Shanghai, P. R. China 2004, pp. 41-81.

[12] L. Bu, L. Song, and C. Shi, "Experimental and theoretical study on flexural behavior of RC beams strengthened with carbon fiber plates," Journal of Building Structures, vol. 02, pp. 72-79, 2007.

\footnotetext{
Received: May 26, 2015

Revised: July 14, 2015

Accepted: August 10, 2015

(C) Haigen et al.; Licensee Bentham Open.
}

This is an open access article licensed under the terms of the (https://creativecommons.org/licenses/by/4.0/legalcode), which permits unrestricted, noncommercial use, distribution and reproduction in any medium, provided the work is properly cited. 